\title{
Introduction to the special issue of the INTERCOAST graduate training group on coastal and shelf seas in New Zealand and Germany
}

\author{
Katrin Huhn ${ }^{1} \cdot$ Karin R. Bryan ${ }^{2}$ \\ Published online: 14 March 2020 \\ (C) Springer-Verlag GmbH Germany, part of Springer Nature 2020
}

Global and climate change, combined with increasing commercial usage of the coast, including expansion of settlement, intensification of harbour development and ship traffic, fisheries and aquaculture industries and tourism, has strong impact on coastal and shelf-sea areas. The challenges posed by these effects are of geoscientific, socio-economic, and legal interest and require interdisciplinary and international cooperation of the relevant scientific fields to analyse, understand, predict, and - where necessary - to mitigate the changes to the natural environment.

In order to tackle these challenges and with the overarching goal of educating a new generation of scientists, the International Research Training Group INTERCOAST'Integrated Coastal Zone and Shelf-Sea Research'-was initiated in 2009 and funded over the duration of 9 years. INTERCOAST was a collaboration project between the universities of Bremen (Germany) and Waikato (New Zealand). Since 2009, more than 35 highly-motivated and interdisciplinary qualified early-career students successfully completed their doctorates within the framework of INTERCOAST. All of them visited the partner universities for approximately onethird of their 3-year-term and thus were continuously involved in interdisciplinary and international research teams. Their various studies and investigations provided new and unique knowledge regarding oceanographic, sedimentological, biological and chemical processes as well as socio-economic

Katrin Huhn

khuhn@marum.de

Karin R. Bryan

karin.bryan@waikato.ac.nz

1 Marum - Center for Marine Environmental Studies, University of Bremen, Bremen, Germany

2 Environmental Research Institute and School of Science, University of Waikato, Hamilton, Waikato, New Zealand interactions and legal effects. INTERCOAST successfully shed light on the interrelations and interactions of the complex web of natural and human impacts on coastal and shelf seas. Such knowledge is a prerequisite for a sustainable utilisation of coastal and shelf-sea areas. In addition, the $\mathrm{PhD}$ students were exceptionally prepared to tackle the challenges associated with the coastal zones and shelf seas in a world that will change in an unprecedented way in the coming decades, and to compete successfully in an increasingly dynamic job market.

Experiences within the INTERCOAST have shown that such international research training groups are an excellent tool to conduct international and interdisciplinary research projects. INTERCOAST was able to demonstrate that even such an ambitious training program between two universities, which could not be further apart, can be successful. Undoubtedly, it was the complementary expertise of the different scientific fields as well as the complementary expertise of both hemispheres - Germany and New Zealand face contrasting coastal, societal and legal environments - that created new fruitful synergies needed for tackling the complex, stateof-the-art research questions. INTERCOAST research resulted in a number of joint, highly ranked international peerreviewed publications. A selection of these scientific results of the various $\mathrm{PhD}$ projects is provided in the publications of this special volume. 